\title{
ECONOMICS
}

\section{INNOVATION AS A VECTOR FOR THE TRANSFORMATION OF UNIVERSITIES INTO ENTREPRENEURIAL ORGANIZATIONS}

DOI: http://doi.org/10.15350/UK_6/9/25

Larisa Ivanenko ${ }^{1}$

Oleg Andreev²

\section{Abstract}

The relevance of solving the problem of the formation and development of a knowledge management system with effective human capital is determined by the nationwide approach to solving it. Modern civilization has offered the world a new model of the economy, where intellectual capital and effective knowledge management provide a breakthrough of the country among the most developed countries in the world. The inevitability of the entry of domestic education into the world educational space depends significantly on new approaches and goal setting. Achieving a new quality of the domestic educational system, its sustainable development is impossible without major changes in the system, processes, mechanisms for managing the development of the university. The effect of the results obtained from the implementation of the project and its impact on the development of science and technology are determined by the presence of high intellectual capital and its impact on the development of the knowledge management system at the university and the managerial resource of the university.

Key words: knowledge management, innovative economy, knowledge economy, commercialization, entrepreneurial university.

The process of globalization has a significant impact on the socioeconomic system of modern society, including the higher education system.

The higher education system is a complex of institutions that influence the social, legal and financial nature.

Currently, the main vector of transformations taking place in the

\footnotetext{
${ }^{1}$ Larisa IVANENKO, Ph.D. in Economics, Professor, Department "Human Resource Management", National Research University "Samara University", Russia.

${ }^{2}$ Oleg ANDREEV, Ph.D. in Economics, associate professor, Department of Economics, Organization and Strategy for Enterprise Development, Samara State Economic University, Russia.
} 
system of higher education is its improvement. The changes affected all aspects of the functioning of the higher education system: both the organizational and legal base, and the institutional basis of higher education. Along with this, among them should be attributed changes in the requirements for training personnel, thereby placing its qualitative characteristics at the forefront.

The reforms carried out in the system of higher education are caused not only by global processes of globalization, but also by the need to become part of the global educational space.

At present, it is important to perceive the country's position at the present stage, taking into account the quality of human capital, the peculiarity of development and the state of education and the level of use of technology in production.

The higher education system has been undergoing reforms for about 20 years. The direct borrowing of Western standards and the strengthening of the regulatory functions of the state leads to an increase in the number of reporting documents at the teaching staff of universities to the detriment of research.

Scientists believe that the higher education system should play a leading role in effectively ensuring the transition to a knowledge economy.

A review of the economic literature shows that the transfer of innovation through cooperation between universities and industry has become a dynamic problem. Universities and firms have different perceptions of cooperation, which often leads to a lack of trust and communication problems throughout the innovation process, and is transformed into the problem of susceptibility of enterprises to innovations in general. The low level of university-industrial cooperation can be explained by the fact that there is a mismatch between the needs of business and the motives of professors.

The identified problems of university-industrial cooperation are associated with internal factors that the university administration is able to develop independently with the full understanding of the business or research mission of the university.

The development of science and technology is the main accelerator and an important factor for the development of the country's competitive advantage.

In this regard, the economy, which is based on the use of knowledge and technology, is a key factor for the effective indicators of qualitatively new transformations in building a qualitatively new society with high-tech characteristics.

In the modern world, universities as generators of innovation should play an increasingly important role in the transition to a knowledge-based economy. Since it is universities that should determine 
the development of modern science and subsequently become an integrator of the main components of an innovative economy: education-scienceproduction.

Higher education allows countries to use effectively available technologies in the direction of economic growth.

In the works of domestic and foreign scientists are provided various definitions of the concept "education".

C. Freeman and B.-A. Lundvall consider education a specific type of material-spiritual production, which develops under the influence of moral and spiritual values [1].

The authors of this definition give an interpretation of the concept of "education" from the standpoint of the theory of the economy knowledge, a feature of which is a rational combination of spiritual, informational and material production with the decisive role of spiritual production.

We consider such an interpretation to be very relevant, since in the modern world new knowledge is one of the most important sources of competitive advantage at the micro, macro and global levels.

However, C. Freeman and B.-A. Lundvall demonstrate a limited approach to the disclosure of the essence of education, since they do not name either its purpose or its subjects.

Highlighting various aspects of education makes it possible to study it from different points of view, as well as from the perspective of a systematic approach, that is, in the aggregate and the relationship of these aspects.

We agree with the position of C. Freeman and B.-A. Lundvall, who attribute education to the sphere of spiritual production [1].

B. Lundvall considered the interaction processes of the innovation system and the learning economy, according to the results of studies of which he concluded that innovation is not a static indicator, but a dynamic and, moreover, cumulative process.

Higher education institutions do not produce anything except knowledge. The products of their activities are research results and educational services, between which there is a relationship. At the same time, estimating the cost of such products is no less difficult than optimizing industrial production with unknown technology.

B. Aysham and A. Isaksen note that in the modern interactive model of an innovative economy, "knowledge is the main resource, and learning is the main process" [10].

Higher education, scientific research have a direct impact on economic growth. 
Among the new approaches in the innovative development of education can be identified:

- paradigm approach;

- systematic prognostic approach;

- phenomenological and synergetic approaches;

- personality-activity approach.

All these approaches in general determine the innovative elements of the higher education system.

Today, there is no clearly defined model of innovative higher education aimed directly at the market needs of relevant specialists. Each of the models has its positive and negative points. But, it should be noted that not one of them is functioning in its pure form at present and cannot be called innovative.

Currently, they are increasingly leaning toward models of universities directly, because in the conditions of competition in the educational market, as well as the possibility of independent choice of the learning path, universities themselves determine innovative learning parameters [6].

The Kneller and Stevens model uses the stochastic boundaries of higher education analysis. The basic model is associated with the production function defined by the Solow equation, but with the introduction of two stochastic conditions:

$$
Y_{i t}=f\left(K_{i t} L_{i t} H_{i t}\right) \exp \left(-n_{i t}\right) \exp \left(\varepsilon_{i t}\right), \text { where (1) }
$$

$Y_{i t}$ - Country Produced Product (GDP);

$K_{i t}$ - capital assets;

$L_{i t}$ - labor intensity (number of working hours per week);

$H_{i t}$ - human capital;

$n_{i t}-$ reflects economic inefficiency $\left(0<\mathrm{n}_{\mathrm{it}}<1\right)$.

It is assumed that the production function will be determined using factors of production, labor, capital and human capital.

In our model, in our opinion, the definition of the boundary is less satisfactory. The effect of human capital is small, but incorrectly described, which may be due to the presence of $h$ in the part of the model that explains the efficiency. The capital efficiency ratio is much larger, which is consistent with the observed capital factor, while labor efficiency is correspondingly lower.

Ronald G. Ehrenberg [2] considers the behavior models of higher education institutions based on the principles of maximizing utility, which were first used by D. Garwin [3] to explain the decision-making processes 
at universities.

From our point of view, the models do not fully cover issues that consider the effects of higher education on economic growth. In models, microeconomic analysis provides estimates of the impact of education on individual incomes, and authors usually supplement their models with macroeconomic studies that provide estimates of the rate of return, similar to those found in microeconomic studies, in the range of $6-12 \%$ per annum.

B. Backhouse believes that higher education institutions can avoid the inefficiency of nonprofit organizations [8]. We agree with the position of S. Rosen, who came to the conclusion that the recommendation of A. Smith to pay most of the salary from the funds received as payment for tuition would be correct if education was the only product of the university. However, research (both basic and applied) is an important product of higher education institutions, along with training [9].

Despite the many different models that reflect the impact of education on the economic development of the country, they do not take into account factors that are essential. Namely, regional aspects, features of investments in education as costs, etc. are not taken into account.

As a result, when assessing the impact of education on the innovative development of a country, the number of indicators is constantly increasing. Under these conditions, it is advisable to study foreign experience both in the field of organizing innovative education and in the sphere of its influence on the economic growth of the state as a whole.

The following arguments can be made in favor of the need for state support for higher education:

- presence of external effects in the form of innovative technologies and the diffusion of scientific and technological achievements that contribute to increasing the efficiency of social production;

- equality (including financial) in the access of all citizens to education;

- function of higher education as a pillar of basic and secondary education [10].

The state and development of higher education in Russia today is largely determined by international integration processes that have occurred and are taking place in the global system of higher education.

Modern humanitarian discourse is characterized by various contexts of the concept of "globalization of education", appealing to global trends in the formation of global markets, the development of modern information technologies and the transformation of knowledge into a direct productive force.

New technologies for creating information flows, practically unlimited possibilities of the Internet and the growing relevance of education in 
an environment where knowledge becomes obsolete at a high speed, have led to completely new relationships in national educational systems that are gradually transforming into global markets for the provision of educational services.

The influence of globalization processes on the education sector is quite mixed and associated with the emergence of certain problems and contradictions.

Due to the effect of globalization, modern higher education institutions take on numerous social functions, which are not only reduced to the training of specialists.

The determining directions for the development of higher education in the future will be the individualization of education, its internationalization and interdisciplinary relations.

Globalization processes lead to fierce competition in the educational market. This fact is a reflection of the requirements of our time, when new information technologies contribute to the global level of knowledge.

Progressive movement towards a continuous process of improving the quality of the provision of educational services, which in the current situation is a guarantee of the university's stable position in the market.

International partnership is one of the main components of the reform of the education system of the Russian Federation, as it helps to determine the ultimate goals and objectives of the reform through taking into account generally recognized world trends and universally recognized educational standards.

The implementation and development of international relations attracts additional financial resources in the form of grants and technical assistance, which has an impact on increasing the attractiveness of a higher educational institution, improving its image, and as a result, increasing its competitiveness.

On a practical level, it is quite difficult to assess separately the impact of international partnerships on changing the competitiveness of the entire university. It is possible rather to establish a connection between international educational programs and the organizational development of the university.

The problem of ensuring the quality of education is global in nature and is due to global trends in approaches to its solution. It is important to note that the concept of ensuring the quality of education has a broader understanding than the quality management system.

One of the main requirements of stakeholders when consuming educational services is the level of their quality, which must meet the criteria for both the world and domestic labor markets. 
The most objective form of assessing the quality of the organization and implementation of educational activities of a higher educational institution is an external assessment carried out through the international accreditation procedure. The compliance of the organization of the educational, scientific, and educational processes of the university with the standards of a foreign accreditation body, confirmed by the corresponding certificate, is a significant indicator of the university's competitive advantages in both international cooperation and competitiveness in the educational services market as a whole.

The integration processes in the global system of higher education and the reforms implemented in the system of higher education, aimed at training the staff needed by the modern economy, depend on the adequacy of the volumes and coordination of financing mechanisms.

The systemic principles of economic transformation and the formation of a new way of thinking and behavior of business entities in the conditions of economic transformation can be served by the theory of human capital, which defines the key role of education, science and intellectual potential with the characteristic features of public-private partnership. Undoubtedly, a significant factor has appeared in postindustrial society, which must be taken into account. This factor is the intellectual capabilities of the person himself.

Researchers at various levels note the existence of certain difficulties in conducting a comparative assessment of the cost characteristics of the human capital of countries with varying degrees of socio-economic development, thereby affecting the coefficient values of human capital efficiency, which naturally manifests itself in their labor productivity.

The role of the financing mechanism for higher education is the effective use of tools and methods of funding and use of financial resources of universities, the final result of which is its quality and accessibility. At the same time, the sequence and effectiveness of the goals set directly depends on the respective sources of financing, the adequacy of not only their combination among themselves, but also the costs for which they are provided.

In determining the forms and methods of financing the higher education system for public universities, the key is the regulatory method of financing. For non-state universities, financing methods have the nature of mixed financing, based on a combination of the costly method with the mandatory use of components of the normative method. In this case, there is a need to clarify the application of the normative method in the formation and use of various costs for the areas of social direction, including the higher education system.

The quality of human capital is one of the key success factors in the commercialization of technology. 
Education forms a qualitative side of human capital, thereby defining such criteria-specific characteristics as the level of health, material values and the psychological component of human capital. It is this significance that makes it possible to confirm the arguments in favor of the conclusion that education should be a key priority in the development of human capital.

We consider education as the basis for the formation of human capital, namely as a factor, tool, control and indicator of its condition.

As a factor, education includes all stages of education, from primary to higher, from school to retirement, on the principle of "education throughout life." The factor in this case will be considered as the accumulation of knowledge and skills throughout the entire cycle of the formation of human capital. As a factor, education is the starting point in the formation of the quality potential of human capital, thereby combining all periods of knowledge: at home, at school, college, university, company.

As a tool, we consider education through a financial mechanism. In our opinion, the effect of the return on investment in education is more obvious, since a person who has invested in education has a higher chance of receiving higher fees in the future than a person with a lower level of education.

As an indicator it is advisable to consider education as a qualitative component of human capital, since education is a key criterion in determining the well-being of a country, shaping national wealth, affecting diversified all elements of the formation of human capital.

Investing, in our opinion, improves human capital. Investing is the most important condition for the reproduction of human capital. Although it is undoubted that investment in human capital is not the main factor affecting its qualitative characteristics.

What is needed is not just investment, but real, meaningful activity that will become the "engine" for the reproduction of human capital. Therefore, effective investment in human capital creates sufficient conditions in order to increase the competitiveness and efficiency of the state economy, which, in turn, is due to the strengthening of the intellectual characteristics of human capital and the efficient use of labor resources.

Some studies dispute the role of scientists in the commercialization of scientific research, highlighting the "market" and "expert" orientation of scientists. At the same time, US scientists recognize and accept the role of the entrepreneur, but put in the first place the role of the researcher, used in the financial support of the higher education system. An important condition for the commercialization of university technology is to ensure its information transparency.

Current trends in the economic development of Russia require the integration of components and their systematic work. 
Currently, a strategic partnership between universities and business is needed. Most universities are at the initial stage of the development of entrepreneurial infrastructure or, as foreign scientists call it, the entrepreneurial ecosystem. A new focus on commercialization and knowledge creates a certain degree of uncertainty role of universities. However, an entrepreneurial university is a command of the time, and if a university declares this mission, then the above factors can achieve the goal with less loss.

\section{References}

[1] Freeman C. The National Systems of Innovation in historical perspective. // In Cambridge journal of economics. - London, 1995. - P. 5-24.

[2] Ehrenberg, Ronald. Adam Smith goes to College: An Economist becomes An Academic Administrator // The Journal of Economic Perspectives. - 1999. - Vol. 13, No. 1. - P 99-116.

[3] Garvin, David. The Economics of University Behavior. - New York: Academic Press. - 1980. - $28 \mathrm{p}$.

[4] Hansen G., Prescott E. (1998) Malus to Solow: NBER Working Paper. - N 6858.

[5] Stolbov M.I. The influence of the financial market on economic growth: Author's thesis, Ph.D. in Economics. - M.: MGIMO, Ministry of Foreign Affairs of the Russian Federation, 2017. - 28 p.

[6] Solow R. (1956) A Contribution to the Theory of Economic Growth // Quarterly Journal of Economics. - Vol. 70. - P. 65-94.

[7] Economic growth: theory and practice // Russian Foreign Economic Bulletin. No. 7. - pp. 18-19.

[8] Backhaus, J.B. The University as an Economic Institution: The Political Economy of the Althoff System, also published in Journal of Economic Studies. - 1993. Vol. 20, No. 4/5.

[9] Rogge, B. and Goodrich, P.F. Education in a Free Society / in Burleigh, A.H. (Ed.), Education in a Free Society, Liberty Fund, Indianoplis. - 1973. - P. 29-55.

[10]Gelvanovsky M.I. Neo-economics and the development strategy of the Russian economic system // In the book "Neo-economics" / under. ed. of prof. A.V. Buzgalina. - M.: Moscow State University, 2014.

[11]Sergeev M. How to overcome obstacles to the knowledge economy. - [Electronic resource: www.politcom.ru/].

[12]Pashkus V.Yu. "New Economy": Features and Problems of Formation // Economic Policy of Russia: Federal and Regional Aspects / Ed. by F.F. Rybakova, G.E. Alpatova. - SPb.: Educational Center for Economics and Management, 2016/ 